http://jmscr.igmpublication.org/home/ ISSN (e)-2347-176x ISSN (p) 2455-0450

crossref DOI: https://dx.doi.org/10.18535/jmscr/v8i11.87

\title{
Pattern and Impact of anxiety disorders in chronic kidney disease
}

\section{Authors \\ Dr Ezeme MS ${ }^{1}$ MBBS, FMCP Sych; Dr Okafor $\mathrm{UH}^{2}$ MBBS, FMCP; Dr Anozie $\mathbf{T}^{\mathbf{3}}$ MBBS}

${ }^{1}$ Consultant Psychiatrist, Department of Internal Medicine, Enugu State University of Science and

Technology Enugu, Nigeria

${ }^{2}$ Consultant Nephrologist, Department of Internal Medicine, Enugu State University of Science and

Technology Enugu, Nigeria

${ }^{3}$ Medical Officer, Department of Internal Medicine, Enugu State University Teaching Hospital Enugu,

Nigeria

*Corresponding Author

Dr Ezeme Mark Sunday

Enugu State University of Science and Technology, Enugu Nigeria

\begin{abstract}
Background: Many studies have reported the occurrence of anxiety disorder in kidney disease, but only very few have tried demonstrating the relevance and the relative rate of different types of anxiety disorders in chronic kidney disease (CKD).
\end{abstract}

Aim: To find the distribution of different categories of anxiety disorders and the influence in the management of patients with CKD.

Method: This was a cross-sectional study of consecutive attendees of CKD patients at the renal unit of Enugu State University Teaching Hospital, Enugu using MINI International Neuropsychiatric Inventory, clinical and laboratory parameters collected from the patients`folders. Data were analyzed with statistical package of social science version 20. A p-value of $\leq 0.05$ was considered statistically significant and confidence interval was at $95 \%$.

Result: Commonest anxiety disorders found among the participants were panic disorder and generalized anxiety disorder, and $20.3 \%$ of them had one type of anxiety disorder or the other. Among these anxious participants, $83.9 \%$ of them were on haemodialysis, and $64.52 \%$ were classified stage 5 kidney disease.

Conclusion: Anxiety disorder is prevalent in kidney disease, and clinicians should have high index of suspicion since its presence may be indicative of severe disease.

Keywords: Pattern; Impact; Anxiety disorder; Kidney disease.

\section{Introduction}

Anxiety disorders are psychological conditions that present with features of excessive fears, anxiety and related behavioural disturbances. They are different from the developmentally normative fear or anxiety because they are excessive and persistent beyond appropriate periods and also differ from transient fear or anxiety, often stress-induced because they are persistent (typically lasting 6 months or more) (APA 2013). These anxiety disorders occur in absence of any other psychiatric, medical or 
substance use disorder. Many anxiety disorders manifest in childhood and may persist till adulthood if not treated. Most of the anxiety disorders are commoner in females than males in a ratio of 2:1 (APA 2013).

Individuals with specific phobia characteristically present with fear or anxiety or avoidance of circumscribed objects or situations. These features are almost always immediately precipitated by the feared object/situation to such a degree that is sustained and disproportionate to the actual perceived risk. In social anxiety disorder (social phobia), there is fear or anxiety or avoidance of social interactions and situations which may involve criticism or scrutiny. For example: meeting unfamiliar people, speaking in public, performing in front of others etc. The individual usually perceive himself/herself as being inferior, negatively evaluated, humiliated or rejected. Panic disorder is the experience of episodic, unexpected panic attacks with persistent concern or worry about having more attacks which may result to death or one going crazy and associated physical symptoms like chest tightness, breathlessness, numbness/tingling sensation. Those having agoraphobia are fearful and anxious about places or situations where escape might be difficult or help might not be available in event of developing panic-like symptoms or other incapacitating or embarrassing features. The usual complaints of persons with generalized anxiety disorder are sustained and excessive anxiety and worries about several issues in life the person finds difficult to control. In addition, the individual experiences physical symptoms like restlessness, fatigue, poor concentration, irritability, muscle tension and sleep disturbances (APA 2013).

From the foregoing, a number of common physical complaints are symptoms of anxiety disorders, such as palpitation, tremor, difficulty in attention and concentration, restlessness, indigestion, tingling sensation, numbness, breathlessness and diaphoresis (APA 2013; Stein, Sareen 2015), thereby confusing the diagnosis of cardiovascular, pulmonary and neurological diseases. Furthermore, there is marked overlap in the symptomatology of anxiety disorders and depressive disorder coupled with the high tendency of the 2 conditions co-existing in the general population and in patients with chronic kidney disease (Cukor, Coplan, Brown, Friedman, Newville 2008; Cukor, Coplan, Brown, Peterson, Kimmel 2008). Sleep apnea and other sleep disorders which are quite common in End Stage Renal Disease (ESRD) patients. (Merlino, Piani, Dolso, Adorati, Cancelli 2006); the potential overlap of symptoms of anxiety disorder with complications of uremia; fatigue which may be related to diverse organ system disorders in ESRD, such as anemia or myopathies; difficulty concentrating which may reflect uremic encephalopathy; and cognitive dysfunction which is increasingly recognized as a complication of ESRD are other diagnostic challenges in patients with chronic kidney disease (Kurella, Chertow, Fried, Cummings, Harris 2005).

Psychiatric disorders usually co-exist with most chronic illnesses and especially with chronic kidney disease (CKD) (Assari 2018). Studies showed that anxiety symptoms are at least two times higher in CKD patients in comparison to general population (Kessler, Chiu, Demler, Merikangas, Walters, 2005; Feroze, Martin, Kalantar-Zadeh, Kim, Reina-Patton 2012). Hospital stay as a result of psychiatric disorders especially depression, anxiety, and substance abuse are 1.5 to 3 times more common in CKD patients than in population of individuals with other chronic diseases (Kimmel, Thamer, Richard, Ray 1998). The rate of anxiety disorders in haemodialysis (HD) patient has been estimated at $12 \%-52 \%$ in several studies (Murtagh, AddingtonHall, Higginson 2007). Cukor et al. (Cukor, Coplan, Brown, Friedman, Newville 2008) using semi-structured clinical interview (SCID-IV) found that $45.7 \%$ of the 70 randomly selected HD patients in a single dialysis center in Brooklyn, New York, met criteria for an anxiety disorder. They also reported that the commonest anxiety 
disorders among the patients were specific phobia and panic disorder. At Lagos, Campbell et al using Schedule for Clinical Assessment in Neuropsychiatry (SCAN) studied psychiatric morbidities in patients with end stage renal disease and reported $21.4 \%$ prevalence rate of anxiety disorder among the participants (Campbell, Olangunji, Oyatokun, Adeyemi 2014). The presence of anxiety symptoms could have an influence on patients with CKD who did not require dialysis at first. For instance, Loosman et al found that among patients with CKD who were not yet on dialysis, the presence of anxiety symptoms showed a trend toward death or commencement of dialysis (Loosman, Rottier, Honig, Siegert 2015). In patients undergoing Peritoneal dialysis (PD), depression and anxiety symptoms have been noted to increase the likelihood of adverse outcomes. Juergensen et al, have demonstrated that patients on PD who reported higher scores for anxiety and depression were more likely to develop peritonitis within the following 12 months (Juergensen, Juergensen, Wuerth 1996). The presence of anxiety disorder in patients on HD has been observed to result in a significantly lower quality of life than patients with no psychopathology, and an even lower quality of life (QoL) than patients with only a depressive disorder (Cukor, Ver Halen, Fruchter 2013; Loosman, Rottier, Honig, Siegert 2015). Furthermore, anxiety disorders place patients at higher risk for concomitant substance abuse (Stein, Sareen 2015). An estimated 35\% of patients with anxiety disorder in the general population abuse alcohol and other drugs (Stein, Sareen 2015; Robinson, Sareen, Cox, Bolton 2009).

Anxiety disorders can occur at different times and with a variety of features in the course of chronic kidney disease including during haemodialysis. A patient seemingly irritable and with irrational behaviours may be exhibiting features of panic disorder, post-traumatic stress disorder, and/or generalized anxiety disorder. Hence, clinical assessment for anxiety disorders may be necessary when: dialysis is to be initiated; coexistent depression is suspected; there is of major life events/stressors; marked changes have occurred in the patients' clinical status, like if evidence of dietary or medication nonadherence, such as hyperphosphatemia is noted; or patient becomes uncooperative in the dialysis unit (Cohen, Cukor, Kimmel 2016). If anxiety disorder is diagnosed, then simultaneous evaluation for depression and risk of suicide is always indicated (Stein, Sareen 2015).

Not many studies have tried to elucidate the presence of different types of anxiety disorders in chronic kidney disease patients. In this study, we aimed at highlighting the rate of occurrence of anxiety disorders and the extent they can influence disease progression and management.

\section{Materials and Method Study population}

This was a hospital based cross-sectional study of patients with chronic kidney disease who presented to the renal unit of Enugu State University Teaching Hospital Enugu from $1^{\text {st }}$ November 2018 to $30^{\text {th }}$ April 2019.

\section{Ethical Approval}

The study was approved by ethical committee of the hospital.

\section{Procedure}

Consecutive attendees with diagnosis of chronic kidney disease who gave informed consent for the study were recruited. The clinical and laboratory parameters of the patients were obtained from the patients` folder. Diagnosis of different types of anxiety disorders were made using their respective module of MINI International Neuropsychiatric Inventory (MINI).

MINI International Neuropsychiatric Inventory The M.I.N.I. is a short structured diagnostic interview developed jointly by psychiatrists and clinicians in the United States and Europe to identify DSM-IV and ICD-10 psychiatric disorders. It was designed to meet the need for a short but accurate structured psychiatric interview for multi-centre clinical trials and epidemiology 
studies. This instrument has 3 versions: M.I.N.I. Plus, M.I.N.I. Screen and M.I.N.I. Kid. In this study, M.I.N.I-Plus (Anxiety disorder modules) was used to confirm the diagnosis of different categories of anxiety disorder. In a validation study carried out in University of South Florida in Tampa and INSERM in Paris, Composite International Diagnostic Interview (CIDI) and Structured Clinical Interview for DSM-III-R (SCID) were compared with M.I.N.I. in France and United States. Overall, the results were very positive, the data suggested that the M.I.N.I. succeeded in reliably and validly eliciting the symptom criteria used in making DSM-III-R and ICD-10 diagnoses and did so in less than half the time needed for the SCID or the CIDI. (Sheehan, Lecrubier, Sheehan, Amorim, Janav 1998)

\section{Data Analysis}

Data obtained were analyzed with statistical package of social science version 20. The variables were expressed as percentages, means and standard deviation using descriptive statistics. A p-value of $\leq 0.05$ was considered statistically significant and confidence interval was at $95 \%$.

\section{Results}

The mean age of the 153 participants was $51.4 \pm$ 15.5 years. The majority of the participants were male gender. Panic disorder and generalized anxiety disorder were most common among them. About 1/5th of them had one category of anxiety disorder or the other, over $4 / 5^{\text {th }}$ of the anxious participants were on haemodialysis and approximately every 6.5 out of 10 of them were classified stage 5 kidney disease.

Table 1: Demographic characteristics of the participants

\begin{tabular}{|c|c|c|c|}
\hline \multirow{2}{*}{\multicolumn{4}{|c|}{$\begin{array}{l}\text { Characteristics } \\
\text { Age (years) }\end{array}$}} \\
\hline & & & \\
\hline Mean & & & \\
\hline Median & & & \\
\hline Standard deviation \pm 15.5 & & & \\
\hline Range & & & \\
\hline Gender N (\%) & 97 (63.4) & $56(36.6)$ & 153 \\
\hline
\end{tabular}

Table 2: Distribution of anxiety disorders among the participants

\begin{tabular}{|l|c|c|c|c|}
\hline Characteristics & Male & Female & Total & $\mathrm{p}$ \\
\hline Anxiety disorders & & & & \\
\hline No N (\%) & $79(51.6)$ & $43(28.1)$ & $122(79.7)$ & .63 \\
\hline Yes N (\%) & $18(11.8)$ & $13(8.5)$ & $31(20.3)$ & \\
\hline Panic disorder & & & & \\
\hline No N (\%) & $91(51.5)$ & $47(30.7)$ & 138 & .048 \\
\hline Yes N (\%) & $6(3.9)$ & $9(5.9)$ & 15 & \\
\hline Agoraphobia & & & & \\
\hline No N (\%) & $96(62.7)$ & $55(35.9)$ & 151 & .70 \\
\hline Yes N (\%) & $1(0.7)$ & $1(0.7)$ & 2 & \\
\hline Social phobia & & & & \\
\hline No N (\%) & $92(60.1)$ & $56(36.6)$ & 148 & .84 \\
\hline Yes N (\%) & $5(3.3)$ & $0(0.0)$ & 5 & \\
\hline Generalized Anxiety disorder & & & & \\
\hline No N (\%) & $89(58.2)$ & $49(32.0)$ & 138 & .39 \\
\hline Yes N (\%) & $8(5.2)$ & $7(4.6)$ & 15 & \\
\hline
\end{tabular}




\section{JMSCR Vol||08||Issue||11||Page 504-511||November}

Figure 1: Haemodialysis among the anxious participants.

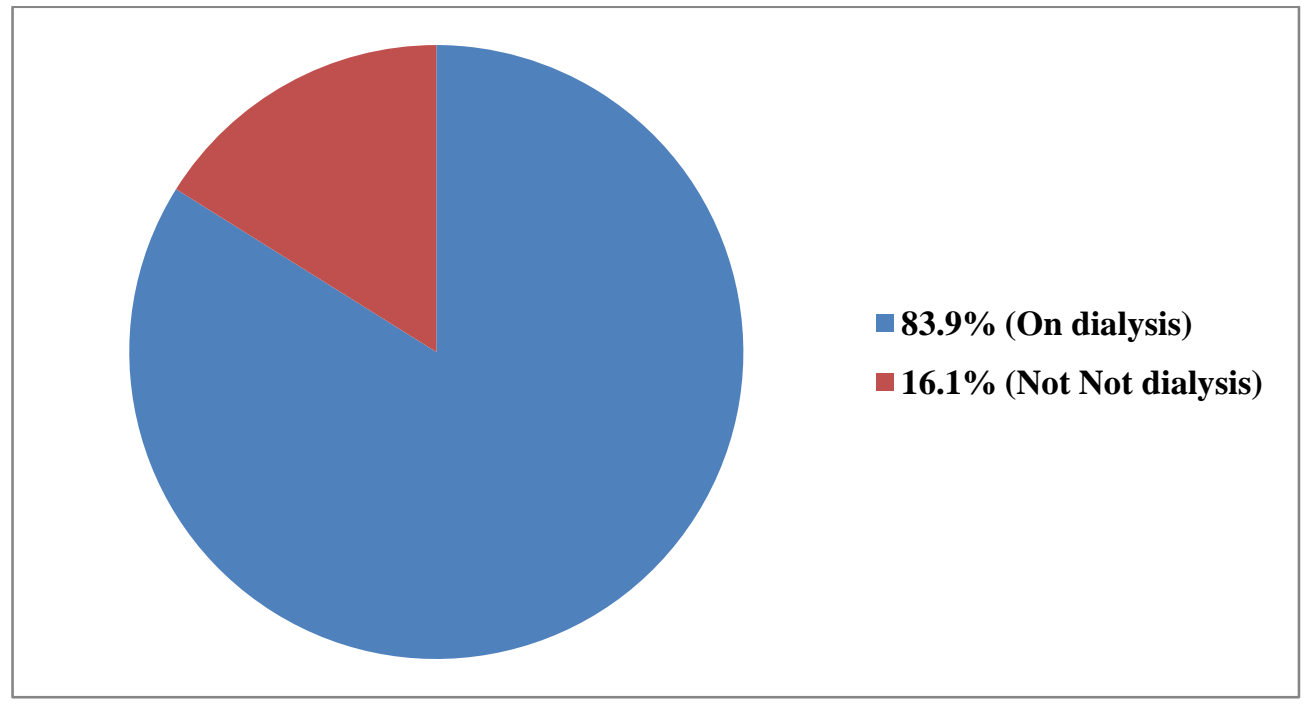

Figure 2: Stage 5 kidney disease and the anxious participants

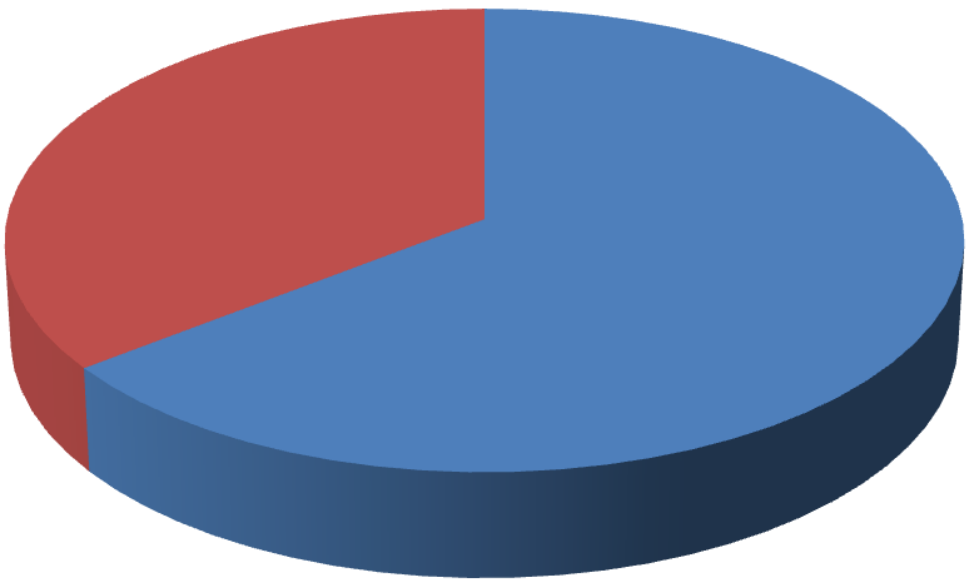

$\square$ Those with stage 5 kidney disease $=64.52 \%$

- Those with other stage of kidney disease $=$ $35.48 \%$

\section{Discussion}

Anxiety disorder has been noted as the second most common psychological disorders found among patients with CKD (Hiricare, Tais PérezDominguez, Armando Rodríguez-Pérez, Miguel. García-Bello 2012). It seems like a warning response manifesting in circumstances of danger, threat or change in life situations. In this study, the prevalence of anxiety disorders in the study population was found to be $20.3 \%$. This is comparable to $19.7 \%$ reported in Saudi Arabia in a cross-sectional study of CKD patients 
undergoing haemodialysis (Goh, Griva 2020). However, our finding is at variance with another research carried out in Brooklyn New York using Semi-structured Clinical Interview (SCID-IV) involving randomly selected 70 patients on haemodialysis whereby $47.5 \%$ of them were identified to have anxiety disorder (Cukor, Coplan, Brown, Friedman, Newville 2008). This discrepancy may be as a result of differences in the individual questionnaires used and the socioeconomic differences of the studied population.

Cukor et al (Cukor, Coplan, Brown, Friedman, Newville 2008) reported that the most common anxiety disorder in CKD patient were panic disorder and specific phobia, however, this finding is not in total conformity with the result of this research which identified generalized anxiety disorder and panic disorder as the commonest of the anxiety disorders in CKD patients. This result can be understood from the fact that CKD is a very stressful medical condition, and generalized anxiety disorder has been observed to have a positive link with stressful events, and some of them may become chronic when the stressor persists. Stressful life events involving losses increase the risk of developing depression and generalized anxiety disorder (Kendler, Hettema, Butera, Gardner, Prescott 2003). However, life events characterized by danger are more prevalent in individuals who eventually present features of generalized anxiety disorder. Panic disorder on the other hand is characterized by repeated episodes of panic attacks which usually present prominently as a particular form of fear response. The state of fear is often associated with sudden rise of autonomic arousal that may result in fight and flight action and thought of immediate danger (APA 2013). Deteriorating health status and tendency of undergoing certain medical procedures like dialysis or kidney transplant to mention only but a few, are glaring feared situations and immediate danger that CKD patients are exposed to. In other words, panicking may explain why some CKD patients are irritable, uncooperative and even refuse treatment.
The result of this study also showed that among the $20.3 \%$ participants who had anxiety disorder, $83.9 \%$ of them were on haemodialysis, while only $16.1 \%$ of them were not on dialysis. However, haemodialysis in CKD patient most times is indicative of an end stage disease and also a severe disease. Hemodialysis requires the patient to adapt to certain restrictions, such as the dietary control, fluid intake, chronic pain and discomfort associated with puncturing the arteriovenous fistula on the day of dialysis, frequent hospital stays, as well as more frequent injuries during the patient's weakened state after dialysis. Also, problems in daily functioning, and fear of the future undoubtedly influence the onset of symptoms of depression and anxiety (Hmwe, Subramanian, Tan, Chong 2015; Gerogianni, Babatsikou 2014; Gerogianni KG, Babatsikou 2013). The source of the patient's anxiety are also invasive procedures accompanying hemodialysis such as: inserting a needle into the arteriovenous fistula, implanted central venous catheters, alarm sounds going off in the dialysis machine and renal staff changing shift at the dialysis station (e.g. a lack of a permanent nurse who punctures the fistula "properly") (Feroze, Martin, KalantarZadeh, Kim, Reina-Patton 2012). Long-term dialysis interferes and leads to an unfavourable self-image, leading to many negative emotions such as despondency, anger, dissatisfaction and disappointment (Wruk-Złotowska A 2006). Furthermore, it has also been demonstrated in this study that $64.52 \%$ of these anxious participants were in the stage 5 kidney disease. This observation tries to buttress fact that anxiety disorder in patients with chronic kidney disease may be a sign of severe disease so that appropriate measures may need to be taken.

\section{Conclusion}

Anxiety disorder is prevalent in kidney disease. Panic disorder and generalized anxiety disorder occur commonly in CKD. In the course of management of these patients, detection of coexisting anxiety disorder may signify severe 
illness. Further studies to exactly delineate the implication of coexisting anxiety disorders in chronic kidney disease patients is highly recommended.

\section{Acknowledgement}

Many thanks go to the staff of medical out-patient department and renal unit of Enugu State University Teaching Hospital Enugu, Nigeria.

\section{References}

1. American Psychiatric Association 2013. Diagnostic and statistical manual of mental disorders, 5th Ed., Arlington, VA, American Psychiatric Association.

2. Assari S 2018. Chronic kidney disease, anxiety and depression among American blacks; does ethnicity matter? https://www.ncbi.nlm.nih.gov/pmc/articles /PMC6687323/ Int J Travel Med Glob Health. 2014 2:133-139.

3. Campbell EA, Olangunji AT, Oyatokun BO, Adeyemi JD 2014. Psychiatric morbidities and associated factors among individuals with end-stage renal disease in Lagos Nigeria. Nigerian Quarterly Journal of Hospital Medicine; vol 24 (3).

4. Cohen SD, Cukor D, Kimmel PL 2016. Anxiety in patients treated with haemodialysis. Clin J Am Soc Nephrol; 11: 2250-2255. doi: 10.2215/CJN.02590316.

5. Cukor D, Coplan J, Brown C, Friedman S, Newville H, Safier M, Spielman LA, Peterson RA, Kimmel PL 2008. Anxiety disorders in adults treated by hemodialysis: a single-center study. Am J Kidney Dis; 52: 128-136.

6. Cukor D, Coplan J, Brown C, Friedman S, Newville H, Safier M, Spielman LA, Peterson RA, Kimmel PL 2008. Anxiety disorders in adults treated by hemodialysis: a single-center study. Am J Kidney Dis; 52: 128-136.
7. Cukor D, Coplan J, Brown C, Peterson RA, Kimmel PL 2008. Course of depression and anxiety diagnosis in patients treated with hemodialysis: a 16monthfollow-up.ClinJAm Soc Nephrol; 3: 1752-1758.

8. Cukor D, Ver Halen N, Fruchter Y 2013. Anxiety and quality of life in ESRD. Semin Dial;26(3):265-268.

9. Feroze U, Martin D, Kalantar-Zadeh K, Kim JC, Reina-Patton A, Kopple JD 2012. Anxiety and depression in maintenance dialysis patients: preliminary data of a cross-sectional study and brief literature review. J. Ren. Nutr; 22, 207-210. doi: 10.1053/j.jrn.2011.10.009.

10. Feroze U, Martin D, Kalantar-Zadeh K, Kim JC, Reina-Patton A, Kopple JD 2012. Anxiety and depression in maintenance dialysis patients: preliminary data of a cross-sectional study and brief literature review. J Ren Nutr; 22:207-210.

11. Gerogianni KG, Babatsikou PF 2013. Identification of stress in chronic haemodialysis. Health Sci J; 7:169-176.

12. Gerogianni KS, Babatsikou PF 2014. Psychological aspects in chronic renal failure. Health Sci J; 8:205-214.

13. Goh ZS, Griva K 2018. Anxiety and depression in patients with end-stage renal disease: impact and management challenges - a narrative review. Int $\mathbf{J}$ Nephrol Renovasc Dis; 11:93-102.

14. Hiricare, Tais Pérez-Dominguez, Armando Rodríguez-Pérez, Miguel A. García-Bello et al 2012. Progression of chronic kidney disease. Prevalence of anxiety and depression in autosomal dominant polycystic kidney disease. Nefrologia; 32 (3): 275-418. DOI: 10.3265/Nefrologia.pre2012.Feb.11379.

15. Hmwe NT, Subramanian P, Tan LP, Chong WK 2015. The effects of acupressure on depression, anxiety and stress in patients with hemodialysis: A 
randomized controlled trial. Int J Nur Stud; 52:509-518.

16. Juergensen PH, Juergensen DM, Wuerth DB, et al 1996. Psychosocial factors and incidence of peritonitis. Adv Perit Dial;12:196-198.

17. Kendler KS, Hettema JM, Butera F, Gardner CO, Prescott CA 2003. Life event dimensions of loss, humiliation, entrapment and danger in the prediction of onsets of major depressive disorder and generalized anxiety. Arch Gen Psychiatry; 60: 789-796.

18. Kessler R. C., Chiu W. T., Demler O., Merikangas K. R., Walters E. E. 2005. Prevalence, severity, and comorbidity of 12-month DSM-IV disorders in the National Comorbidity Survey Replication. Arch. Gen. Psychiatry; 62, 617-627. doi: 10.1001/archpsyc.62.6.617.

19. Kimmel PL, Thamer M, Richard CM, Ray NF 1998. Psychiatric illness in patients with end-stage renal disease. Am. J. Med; $105,214-221$. doi: 10.1016/S00029343(98)00245-9.

20. Kurella M, Chertow GM, Fried LF, Cummings SR, Harris T, Simonsick E, Satterfield S, Ayonayon H, Yaffe K 2005. Chronic kidney disease and cognitive impairment in the elderly: the health, aging, and body composition study. J Am Soc Nephrol; 16: 2127-2133.

21. Loosman WL, Rottier MA, Honig A, Siegert CE 2015. Association of depressive and anxiety symptoms with adverse events in Dutch chronic kidney disease patients: a prospective cohort study. BMC Nephrol;16(1):155.

22. Merlino G, Piani A, Dolso P, Adorati M, Cancelli I, Valente M, Gigli GL2006. Sleep disorders in patients with end-stage renal disease undergoing dialysis therapy. Nephrol Dial Transplant; 21: 184-190.
23. Murtagh FE, Addington-Hall J, Higginson IJ 2007 The prevalence of symptoms in end-stage renal disease: a systematic review. Adv Chronic Kidney Dis; 14: 8299.

24. Robinson J, Sareen J, Cox BJ, Bolton JM 2011. Role of self-medication in the development of comorbid anxiety and substance use disorders: a longitudinal investigation. Arch Gen Psychiatry; 68: 800-807.

25. Sheehan DV, Lecrubier Y, Sheehan KH, Amorim P, Janav SJ, Weiller E et al 1998. The Mini-International Neuropsychiatric Interview (M.I.N.I.): The development and Validation of a Structured Diagnostic Psychiatric Interview for DSM-IV and ICD-10. J Clin Psychiatry; 59(suppl 20): 22-33.

26. Stein MB, Sareen J 2015. Generalized Anxiety Disorder. N Engl J Med, 373: 2059-2068.

27. Stein MB, Sareen J 2015. Generalized Anxiety Disorder. N Engl J Med; 373: 2059-2068.

28. Wruk-Złotowska A 2006. Lęki pacjentów dializowanych. Pielęgniarstwo Polskie; 2:158-166. 